Check for updates

Cite this: J. Mater. Chem. A, 2020, 8 , 9788

\section{The nature of the methylamine-MAPbl 3 complex: fundamentals of gas-induced perovskite liquefaction and crystallization $\uparrow$}

\author{
Dmitry Bogachuk, (D) ab Lukas Wagner, ${ }^{\text {ab }}$ Simone Mastroianni, ${ }^{\text {ac }}$ Michael Daub, (D) d \\ Harald Hillebrecht (iD ${ }^{\text {cd }}$ and Andreas Hinsch*a
}

\begin{abstract}
The liquefaction and recrystallization of $\mathrm{CH}_{3} \mathrm{NH}_{3} \mathrm{Pbl}$, perovskite with methylamine $-\mathrm{MA}^{0} / \mathrm{CH}_{3} \mathrm{NH}_{2}$ gas in solar cells have been intensively studied in the past years, yet the exact mechanisms remained hypothesized and unclear due to lack of experimental evidence. The investigation presented in this work connects the interatomic bonding in the methylamine-MAPbl 3 complex during liquefaction and recrystallization with the crystal morphology and the lifetime of photo-generated carriers in planar and mesoporous layer structures. Raman shift analysis and XRD structural investigation have been performed, showing that $M A^{0}$ gas forms a complex with $\mathrm{MAPbl}_{3}$ via chemisorption of gas molecules to the perovskite crystal surface by replacing $\mathrm{I}^{-}$atoms in the $\mathrm{Pbl}_{6}$ octahedra and via coordination of $\mathrm{MA}^{+}$. Through real-time photoluminescence, the changes in bonding during the liquid-solid transition are related to the radiative charge carrier recombination during the liquefaction and recrystallization. We found that the amount of $M A^{0}$ gas reacting with perovskite determines the crystal morphology, porefilling and, most importantly, the charge carrier lifetime.
\end{abstract}

Received 3rd March 2020

Accepted 28th April 2020

DOI: $10.1039 / \mathrm{dOta02494e}$

rsc.li/materials-a

\section{Introduction}

In the last decade, perovskite photovoltaics (PV) have been investigated by a tremendous number of scientists and researchers, reaching outstanding power conversion efficiencies (PCEs) which in the laboratory have already exceeded the record efficiencies of such mature technology as polycrystalline silicon, Cadmium Telluride (CdTe) and Copper Indium Gallium Selenide (CIGS). ${ }^{1}$

Such rapid development was realized by continuous improvements of the molecular structure, film morphology and physical properties of perovskite crystals. One successful method to achieve this goal was proposed in 2015 by Zhou et al., where a peculiar phenomenon was described in which methylammonium lead iodide $\left(\mathrm{MAPbI}_{3}\right)$ has be liquefied upon exposure to methylamine $\left(\mathrm{CH}_{3} \mathrm{NH}_{2} / \mathrm{MA}^{0}\right)$ gas. ${ }^{2}$ This liquefaction process is reversible and upon removal of the $\mathrm{MA}^{0}$-gas,

${ }^{a}$ Department of Organic and Perovskite Photovoltaics, Fraunhofer Institute for Solar Energy Systems ISE, Heidenhofstr. 2, 79110, Freiburg, Germany

${ }^{b} I N A T E C H$, Albert-Ludwigs-Universität Freiburg, Emmy-Noether-Str. 2, 79110, Freiburg, Germany

'Materials Research Center FMF, Albert-Ludwigs-Universität Freiburg, Stefan-MaierStr. 21, 79104, Freiburg, Germany

${ }^{d}$ Institute for Inorganic and Analytic Chemistry, Albert-Ludwigs-Universität Freiburg, Albertstr. 21, 79104, Freiburg, Germany

$\dagger$ Electronic supplementary information (ESI) available. CCDC 1997919, 1936930 and 1998017. For ESI and crystallographic data in CIF or other electronic format see DOI: $10.1039 /$ dota02494e crystalline $\mathrm{MAPbI}_{3}$ is formed again. The chemical reaction has been suggested in literature as following:

$$
\begin{aligned}
& \mathrm{CH}_{3} \mathrm{NH}_{3} \mathrm{PbI}_{3}(\mathrm{~s})+x \mathrm{CH}_{3} \mathrm{NH}_{2}(\mathrm{~g}) \leftrightarrows \\
& \qquad \mathrm{CH}_{3} \mathrm{NH}_{3} \mathrm{PbI}_{3} \cdot x \mathrm{CH}_{3} \mathrm{NH}_{2}(\mathrm{l})
\end{aligned}
$$

This process has often been used as a post-treatment step to improve film morphology and crystal quality. ${ }^{3-6}$ Enhancements of photovoltaic properties of solar cells using methylamine gas were repeatedly reported due to an improved film quality, charge carrier lifetime, perovskite film homogeneity and more favorable crystallinity, ${ }^{5,7-11}$ bridging to an efficiency of above $20 \% .{ }^{12,13}$ On the technological side, Noel et al. have proposed to dissolve perovskite precursor in a mixed solvent of acetonitrile (ACN) and $\mathrm{MA}^{0}$ to produce a solution which can be used for manufacturing high-efficient perovskite solar cells with PCE of $18 \%{ }^{14}$ In this process the solvating capability of ACN was increased by methylamine bubbling, leading to formation of a clear perovskite solution. In 2018, we have developed a dropcasting method where a similar approach can be used for infiltration of the porous scaffold of carbon-based printable, low-cost, hole conductor-free perovskite solar cells (C-PSCs). The champion device had a $V_{\text {oc }}$ of over $1 \mathrm{~V}$ and a stabilized efficiency of $12.6 \%$ certified by Fraunhofer ISE CalLab. ${ }^{15}$ Consequentially, manufacturing the photo-absorber layer of a PV device using methylamine-perovskite interaction establishing itself as a promising, cost-effective approach, that can be implemented on a large scale module production. ${ }^{16-18}$ 
The question what stands behind the observed mechanism of perovskite liquefaction was already raised in previous reports. Zhou et al. supposed that the lone-electron pair in the nitrogen $(\mathrm{N})$ atom of methylamine gas interacts with $\mathrm{PbI}_{6}$ octahedra, which leads to a liquefied state. ${ }^{2}$ It has also been noted that the "molten state" can be achieved by exposing the precursor salt $\mathrm{PbI}_{2}$ to methylamine or other amines which suggests that the reaction is driven by interaction between the alkylamines and $\mathrm{Pb}(\mathrm{II}) .^{7,8,19-21}$ The interaction between $\mathrm{MAPbI}_{3}$ and $\mathrm{MA}^{0}$ gas was also described as a moderate ligand coordination of the lead atoms changing the lead halide framework. ${ }^{8}$ Simultaneously, Rand et al. have reported that the proton transfer from $\mathrm{PbI}_{2}$ to alkylamines results in the formation of $\mathrm{Pb}$-amide bonds, responsible for the perovskite liquefaction. ${ }^{20}$ Also the formation of colloids has been attributed to the presence of a $x \mathrm{MA}^{0}-\mathrm{MAPbI}_{3}$ complex which is strengthened by witnessing Tyndall effect in this complex. ${ }^{8,22}$ However, despite the substantial research in the field of $\mathrm{MA}^{0}$ gas treatment of $\mathrm{CH}_{3} \mathrm{NH}_{3} \mathrm{PbI}_{3}$ perovskites ${ }^{2-6,8-10,13,14,21-23}$ the exact mechanism of the methylamine-perovskite complex formation (which will be referred to as MPC further in this work) and the chemical bonding in the liquefied state remain unclear due to lack of experimental evidence. In particular the following underlying questions of this method remain pending: (1) how does the stoichiometry of the MPC formation reaction affects the crystal parameters, (2) what dictates the crystallization dynamics during up-take and removal of the $\mathrm{MA}^{\mathrm{O}}$-gas and (3) what happens to the $\mathrm{MAPbI}_{3}$ lattice when it is exposed to $\mathrm{MA}^{0}$ gas molecules. We accentuate that the answers to those questions in this work contain vital importance not only for the fundamental chemistry scientists but also for numerous researchers in the perovskite community, which aim to reach high device efficiencies.

In this work, we were able to isolate single crystals and to determine the crystal structures of intermediates from the reaction of $\mathrm{MA}^{0}$ with $\mathrm{MAPbI}_{3}$. These empirical results clearly present how $\mathrm{MA}^{0}$ can coordinate $\mathrm{Pb}^{2+}$ and $\mathrm{MA}^{+}\left(\mathrm{CH}_{3} \mathrm{NH}_{3}\right)$ leading to the formation of crystalline materials, which are stable only in the presence of $\mathrm{MA}^{0}$-rich environment. We combine the knowledge of crystalline intermediates to elucidate how does methylamine interact with $\mathrm{MAPbI}_{3}$ perovskite, what are the possible reaction pathways and in particular how the properties of MPC affect the opto-electronic properties of the crystallized perovskite.

We demonstrate by Raman spectroscopy that, upon introduction of methylamine, the lead-halide framework changes through partial replacement of $\mathrm{I}^{-}$with $\mathrm{MA}^{0}$ during its coordination of $\mathrm{Pb}^{2+}$ and $\mathrm{MA}^{+}$. We also show the bonding environment in the molten state and how it correlates with the optoelectronic properties of the recrystallized films. Through realtime photoluminescence (PL) microscopic measurement during crystallization we reveal the underlying mechanisms happening inside a porous layer $\left(\mathrm{ZrO}_{2} /\right.$ graphite which are normally a part of C-PSCs) during the conversion of MPC to crystalline $\mathrm{MAPbI}_{3}$. In addition, we investigate the effect of methylamine/perovskite ratio in the solution on the crystallized absorber layer. Our extensive analysis sheds light onto the chemistry of the MPC, its crystallization kinetics and the mechanisms to control the fundamental properties of perovskite absorber, which define solar cell efficiencies.

\section{Experimental}

\section{Precursor solution preparation}

The $\mathrm{PbI}_{2}$ /MAI (1:1)-DMF complex (purchased from TCI, $99.99 \%$ trace metals basis) was heated at $100^{\circ} \mathrm{C}$ under nitrogen atmosphere and thus a nearly pure $\mathrm{MAPbI}_{3}$ perovskite powder was obtained. The liquefied perovskite using $\mathrm{MA}^{0}$ gas $(\geq 99 \%$, purchased from Linde) of certain amount has been further diluted using acetonitrile with a ratio of $1 \mathrm{mg} \mathrm{MAPbI}_{3}$ to $1 \mu \mathrm{L}$ of ACN (purchased from Carl Roth $>99 \%$ ).

\section{Sample preparation}

The glass plates with fluorine-doped tin oxide on top were treated in an ultrasonic bath containing 3\% deconex OP153 at $60{ }^{\circ} \mathrm{C}$ followed by rinsing with DI water. An ultrasonic treatment at $60{ }^{\circ} \mathrm{C}$ for $1 \mathrm{~min}$ in DI water was further operated to ensure removal of any detergent residual. Glass plates were then blown dry using nitrogen. $\mathrm{ZrO}_{2}$ (Zr-nanoxide paste obtained from Solaronix SA) of $2 \mu \mathrm{m}$ thickness was screen printed on top of glass and sintered at $500^{\circ} \mathrm{C}$ for $30 \mathrm{~min}$, after which the graphitebased counter electrode of $12 \mu \mathrm{m}$ thickness was screen printed, followed by sintering at $400{ }^{\circ} \mathrm{C}$ for $30 \mathrm{~min}$. Samples filled with perovskite in $\mathrm{ZrO}_{2}$ and graphite layers were kept under $\mathrm{MA}^{0}$ environment for 30 minutes to facilitate a better pore impregnation, after which the samples were annealed at $80{ }^{\circ} \mathrm{C}$ for 30 minutes. Perovskite films were spin-coated on glass substrates, pre-treated with plasma and annealed at $80{ }^{\circ} \mathrm{C}$ for 30 minutes.

For the complete perovskite solar cell devices (shown in ESI $\dagger$ ) with carbon-based electrode, a compact $\mathrm{TiO}_{2}$ layer of 25$30 \mathrm{~nm}$ thickness was deposited by spray pyrolysis using a solution comprising $0.05 \mathrm{M}$ of titanium diisopropoxy (bis)acetyl acetone (Sigma Aldrich) diluted with ethanol $(\geq 99.5 \%$ from Carl Roth). Mesoporous layers of $\mathrm{TiO}_{2}$ (paste prepared via mixing Dyesol DSL-18NRT with terpineol in $1: 0.75$ weight ratio) and $\mathrm{ZrO}_{2}$ of $500 \mathrm{~nm}$ and $1 \mu \mathrm{m}$ thicknesses respectively were screen printed and sintered at $500{ }^{\circ} \mathrm{C}$. Afterwards the graphite-based layer (Elcocarb B/SP paste purchased from Solaronix SA) was screen printed and subsequently sintered as described above. The positive and negative electrodes were applied by ultrasonic soldering on the FTO. The applied silver paste on the electrodes completes the architecture of the cell. The device active area was $0.4 \mathrm{~cm}^{2}$.

\section{Characterization}

Raman spectra were measured on a Bruker Vertex 70 with a Bruker RAM II module Nd:YAG laser $(\lambda=1064 \mathrm{~nm})$ in a range of $50-4000 \mathrm{~cm}^{-1}$. X-ray diffraction (XRD) patterns of films were collected with a Bruker D8 diffractometer $(\mathrm{CuK} \alpha=0.1540598$ $\mathrm{nm}$ ) equipped with a Lynxeye detector. The PL images were obtained by OLYMPUS BX50 stereomicroscope and sCMOS camera ("Zyla 5.5 sCMOS" by Andor) with a long-pass filter while the partial illumination of the sample was provided by 
a $623 \mathrm{~nm}$ red light-emitting diode (Thorlabs, SOLIS-623C). Due to the presence of long-pass we can exclude that the recorded signal originates from radiative recombination of free charge carriers and not from the reflectance of the excitation source. Time-resolved PL measurement were conducted using externally triggered CW laser (Coherent Orbis) of $660 \mathrm{~nm}$ wavelength with $100 \mathrm{~mW}$ power, with a fall and rise time (10\% and 90\%) below 2 ns. The laser was triggered to produce rectangularshaped signals at $7 \mathrm{~Hz}$ frequency. The current-density and voltage curves of the devices were measured with a source meter (Keithley 2400) at a scan rate of $50 \mathrm{mV} \mathrm{s}^{-1}$ using a solar simu-

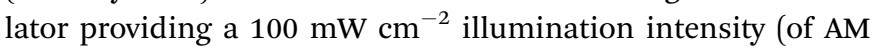
$1.5 \mathrm{G})$.

\section{Result and discussion}

Synthesis and characterization of intermediates $\mathbf{M A}^{\mathbf{0}} / \mathbf{M A}^{+} /$ $\mathbf{P b I}_{2}$

Following the conditions in the course of the liquefaction transformation process, single crystals of several intermediates were isolated and characterized. Passing a stream of $\mathrm{MA}^{\%}$ $\mathrm{CH}_{3} \mathrm{NH}_{2}$ gas over powdered $\mathrm{PbI}_{2}$ yielded a highly viscous liquid from which pale-yellow platelets were crystallized. The crystal structure determination (Table $\mathrm{S} 1 \dagger$ ) revealed a neutral complex of $\mathrm{Pb}$ (II) with the composition $\left(\mathrm{CH}_{3} \mathrm{NH}_{2}\right)_{4} \mathrm{PbI}_{2}$. A simplified description classifies $\left(\mathrm{CH}_{3} \mathrm{NH}_{2}\right)_{4} \mathrm{PbI}_{2}$ as a neutral octahedral complex with two iodine anions in a cis-position (Fig. 1a, details Table $\mathrm{S} 1 \dagger) . \mathrm{CH}_{3} \mathrm{NH}_{2}$ acts as a classical donor ligand to $\mathrm{Pb}^{2+}$.

Passing a strong stream of methylamine evaporated from the cold trap over $\mathrm{MAPbI}_{3}$ was readily liquefied and colorless crystals were precipitated from the $\mathrm{MAPbI}_{3} x \mathrm{MA}^{0}$. They were stable at room temperature if the sample was kept in a closed vessel with pure methylamine as equilibrium gas phase. For the measurement the crystals were directly transferred from the mother liquid into the cold $\mathrm{N}_{2}$-stream of the sc-XRD (at $100 \mathrm{~K}$ ). Further examination revealed a multiply twinned crystal where the idealized structure is based on a face-centered cubic unit cell. The refinement (Table $\mathrm{S} 1 \dagger$ ) yielded a structure model close to the well-known $\mathrm{K}_{2} \mathrm{PtCl}_{6}$ type with octahedral $\left[\mathrm{Pb}\left(\mathrm{CH}_{3} \mathrm{NH}_{2}\right)_{6}\right]^{2+}$ complexes and isolated $\mathrm{I}^{-}$anions (Fig. 1b, details Table $\mathrm{S} 1 \dagger$ ).
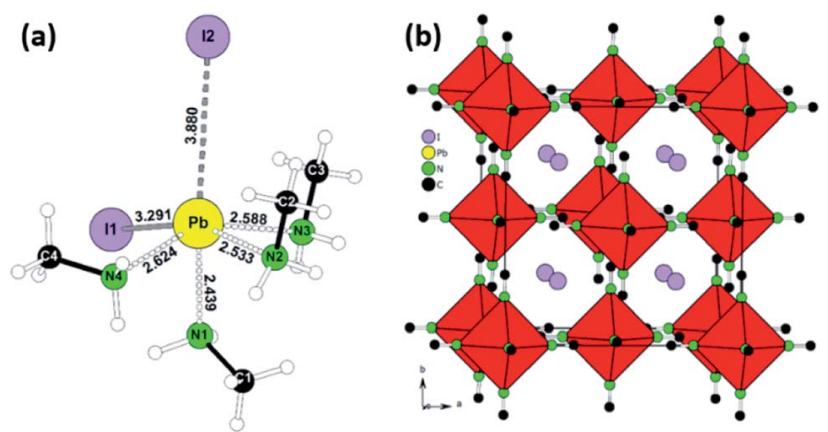

Fig. 1 Visual representation of neutral complex $\mathrm{Pbl}_{2}\left(\mathrm{CH}_{3} \mathrm{NH}_{2}\right)_{4}$ with corresponding bonds lengths. (a) Crystal structure of $\left[\mathrm{Pb}\left(\mathrm{CH}_{3} \mathrm{NH}_{2}\right)_{6}\right] \mathrm{I}_{2}$ idealised as cubic $\mathrm{K}_{2} \mathrm{PtCl}_{6}$ type (b) as derived from the single crystal XRD measurement.
This $\mathrm{K}_{2} \mathrm{PtCl}_{6}$-related structure is a very common motif for hexammine complexes of divalent transition metal halides $\left[\mathrm{M}(\mathrm{II})\left(\mathrm{NH}_{3}\right)_{6}\right] \mathrm{X}_{2}(\mathrm{M}=\mathrm{V}, \mathrm{Cr}, \mathrm{Mn}, \mathrm{Fe}, \mathrm{Co}, \mathrm{Ni} ; \mathrm{X}=\mathrm{Cl}, \mathrm{Br}, \mathrm{I}){ }^{24}$

In some cases, small colorless needles were formed as byproduct which can't be recovered as $\mathrm{MAPbI}_{3}$ in the course of the re-crystallization process. The small needles were characterized by sc-XRD as $\mathrm{Pb}(\mathrm{OH}) \mathrm{I}^{25,26}$ Additionally, pale-yellow platelets were separated from the bulk material, which were characterized as $\left(\mathrm{CH}_{3} \mathrm{NH}_{3}\right)_{5}\left(\mathrm{CH}_{3} \mathrm{NH}_{2}\right)_{2} \mathrm{~Pb}_{2} \mathrm{I}_{9}$. This compound contains $\left[\mathrm{Pb}_{2} \mathrm{I}_{9}\right]^{5-}$ units consisting of two face-sharing octahedra and $\mathrm{MA}^{0} / \mathrm{MA}^{+}$dimers $\left[\mathrm{CH}_{3} \mathrm{NH}_{3}-\mathrm{NH}_{2} \mathrm{CH}_{3}\right]^{+}$bridged by a hydrogen bond (Fig. S1, details Table S1 $\dagger$ ). The formation is explained by moisture according the following reaction:

$$
\begin{aligned}
4 \mathrm{CH}_{3} \mathrm{NH}_{3} \mathrm{PbI}_{3}+4 \mathrm{CH}_{3} \mathrm{NH}_{2}+2 \mathrm{H}_{2} \mathrm{O} \rightarrow \\
\left(\mathrm{CH}_{3} \mathrm{NH}_{3}\right)_{5}\left(\mathrm{CH}_{3} \mathrm{NH}_{2}\right)_{2} \mathrm{~Pb}_{2} \mathrm{I}_{9}+2 \mathrm{~Pb}(\mathrm{OH}) \mathrm{I}+\mathrm{CH}_{3} \mathrm{NH}_{3} \mathrm{I}(2)
\end{aligned}
$$

\section{Composition of $\mathrm{MA}^{\mathbf{0}}-\mathrm{MAPbI}_{3}$ complexes in solution of liquefied $\mathrm{MAPbI}_{3}$ and evolution/precipitation of perovskite}

From the above-mentioned findings, it is strongly suggested that the liquefaction of $\mathrm{MAPbI}_{3}$ in the presence of $\mathrm{MA}^{0}$ is driven by its coordination of $\mathrm{Pb}^{2+}$ and $\mathrm{MA}^{+}$. To gain new insights into the interaction between $\mathrm{MA}^{0}$ and $\mathrm{CH}_{3} \mathrm{NH}_{3} \mathrm{PbI}_{3}$, an MPC solution (diluted in ACN) with high excess of $\mathrm{MA}^{0}$ was produced in a closed vial. The Raman spectrum was then measured as the vial was opened in ambient conditions at room temperature and $\mathrm{MA}^{0}$ gradually left the liquid over a course of 125 minutes throughout which the pale-yellow liquid gradually turned to saturated clear yellow and, consequently with additional annealing, turned dark, resembling crystalline $\mathrm{MAPbI}_{3}$. In the liquified state (Fig. 2, purple) at high $\mathrm{MA}^{0}$ pressure, the most intense peak is at $78 \mathrm{~cm}^{-1}$, followed by a peak at $94 \mathrm{~cm}^{-1}$. Upon opening of the vial, an intermediate state is introduced which has a dominant peak at $104 \mathrm{~cm}^{-1}$ and a smaller peak at $82 \mathrm{~cm}^{-1}$. Finally, upon additional annealing the bands at $94 \mathrm{~cm}^{-1}$ and $82 \mathrm{~cm}^{-1}$ arise. Furthermore, the bands at $155 \mathrm{~cm}^{-1}$ and $290 \mathrm{~cm}^{-1}$ are only present in the MPC and both of them
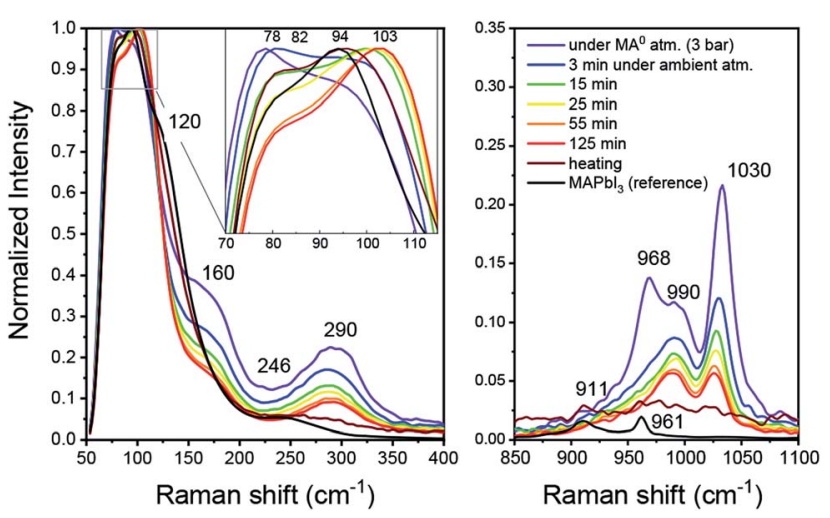

Fig. 2 Raman spectra of a liquified $M A P b{ }_{3} x M A^{0}$ complex (MPC) during liquid-solid conversion as the $M A^{0}$ leaves the complex. Note the shifts in the $70-115 \mathrm{~cm}^{-1}$ region (inset) corresponding to $\mathrm{Pb}-$ I symmetric and asymmetric stretching vibrations, suggesting that the $\mathrm{Pbl}_{6}$ octahedra undergo changes. 
disappear during crystallization, while the new bands at $120 \mathrm{~cm}^{-1}$ and $242 \mathrm{~cm}^{-1}$ occur.

In the context of $\mathrm{MAPbI}_{3}$ Raman shift spectrum, the region between 70 and $120 \mathrm{~cm}^{-1}$ is usually attributed to $\mathrm{Pb}-\mathrm{I}$ framework interactions, such as symmetric and asymmetric $\mathrm{Pb}-\mathrm{I}$ bond stretching. ${ }^{28-31}$ As soon as the vial with the MPC is opened, $\mathrm{MA}^{0}$ molecules start to leave and both peaks shift, indicating a structural reorganization of the $\mathrm{Pb}-\mathrm{I}$ framework (i.e. a change in $\mathrm{Pb}-\mathrm{I}$ valence vibrations) during the transition between the liquid and solid phases. The Raman shifts in wavenumber region of $150-3000 \mathrm{~cm}^{-1}$ is commonly attributed to numerous vibrational modes of organic cations such $\mathrm{CH}_{3}$ bending, $\mathrm{C}-\mathrm{N}$ stretching, $\mathrm{N}-\mathrm{H}$ stretching and others ${ }^{29,32}$ (complete Raman shift spectra are presented in Fig. S2 in the ESI $\dagger$ ). Notably, we highlight the presence of a band at $290 \mathrm{~cm}^{-1}$ existing only in the liquid state under high pressure, which we affiliate with a rotational mode of $\mathrm{MA}^{+}$. In a recent report from Park et al. a similar band at $288 \mathrm{~cm}^{-1}$ was found to be responsible for a rotational mode of $\mathrm{MA}^{+}$cation, which is normally inactive, but can be seen here either due to the fact that in the MPC the local symmetry of $\mathrm{PbI}_{3}$ framework is lower or because $\mathrm{MA}^{+}$form MAI-MA ${ }_{x}^{0}$ during the MPC formation as will be shown later. ${ }^{30}$

As seen from Fig. 2, the band at $290 \mathrm{~cm}^{-1}$ gradually reduces during the crystallization, while the band at $120 \mathrm{~cm}^{-1}$ rises, which can be attributed to $\mathrm{MA}^{+}$libration mode. ${ }^{29}$ In addition, the bands at $1030 \mathrm{~cm}^{-1}$ and $990 \mathrm{~cm}^{-1}$ which nearly ideally correspond to the $\mathrm{CH}_{3}-\mathrm{NH}_{3}$ rocking and $\mathrm{C}-\mathrm{N}$ stretching vibrations respectively for a free $\mathrm{MA}^{+}$in vacuum, vanish during crystallization. ${ }^{32}$ Simultaneously, the bands assigned to the same vibrational modes in $\mathrm{MAPbI}_{3}$ appear at $911 \mathrm{~cm}^{-1}$ and $961 \mathrm{~cm}^{-1}$ for $\mathrm{CH}_{3}-\mathrm{NH}_{3}$ rocking and $\mathrm{C}-\mathrm{N}$ stretching, respectively. Such band shifts suggest the reduction of free $\mathrm{MA}^{+}$ cations and the increase of the $\mathrm{Pb}-\mathrm{I}$ framework symmetry due to insertion of $\mathrm{MA}^{+}$yields recrystallized $\mathrm{MAPbI}_{3}$. In the presence of humidity, $\mathrm{H}_{2} \mathrm{O}$ and $\mathrm{CH}_{3} \mathrm{NH}_{2}$ are reacting in an acid base reaction to produce $\mathrm{MA}^{+}$cations and $\mathrm{OH}^{-}$anions. In this case degassing results in the formation of crystalline $\left(\mathrm{CH}_{3} \mathrm{NH}_{3}\right)_{3}(-$ $\left.\mathrm{CH}_{3} \mathrm{NH}_{3}-\mathrm{NH}_{2} \mathrm{CH}_{3}\right)_{2} \mathrm{~Pb}_{2} \mathrm{I}_{9}$ and colorless rod-shaped crystals of $\mathrm{Pb}(\mathrm{OH}) \mathrm{I}$. $\left(\mathrm{CH}_{3} \mathrm{NH}_{3}\right)_{3}\left(\mathrm{CH}_{3} \mathrm{NH}_{3}-\mathrm{NH}_{2} \mathrm{CH}_{3}\right)_{2} \mathrm{~Pb}_{2} \mathrm{I}_{9}$ is build up by isolated $\left[\mathrm{Pb}_{2} \mathrm{I}_{9}\right]^{5-}$ dimers of face sharing $\mathrm{PbI}_{6}$-octahedra (Fig. 3). Charge balance is achieved by $\mathrm{MA}^{+}$as well as the dimeric (MA$\left.\mathrm{MA}^{0}\right)^{+}$cations. Further degassing yields also $\mathrm{MAPbI}_{3}$, but $\mathrm{Pb}(\mathrm{OH}) \mathrm{I}$ stays as a by-product, which emphasizes that humidity should be avoided during the recrystallization of $\mathrm{MAPbI}_{3}$ with $\mathrm{MA}^{0}$. Thus, the $\mathrm{MAPbI}_{3}$ liquefaction may be driven by two effects, $\mathrm{MA}^{0}$ bonding to $\mathrm{Pb}^{2+}$ atom via lone electron pair as well as by the formation of $\mathrm{MA}^{0}-\mathrm{MA}^{+}$dimers. Very recently (this manuscript had already been submitted at that time), another publication on the liquefaction of $\mathrm{MAPbI}_{3}$ using methylamine gas was published. ${ }^{27}$ In accordance with our own work, they also found the existence of methylammonium-methylamine dimers. The dimers can be regarded as large cations with low charge density, reducing the lattice energy of the corresponding salt, which yields a situation comparable to ionic liquids.

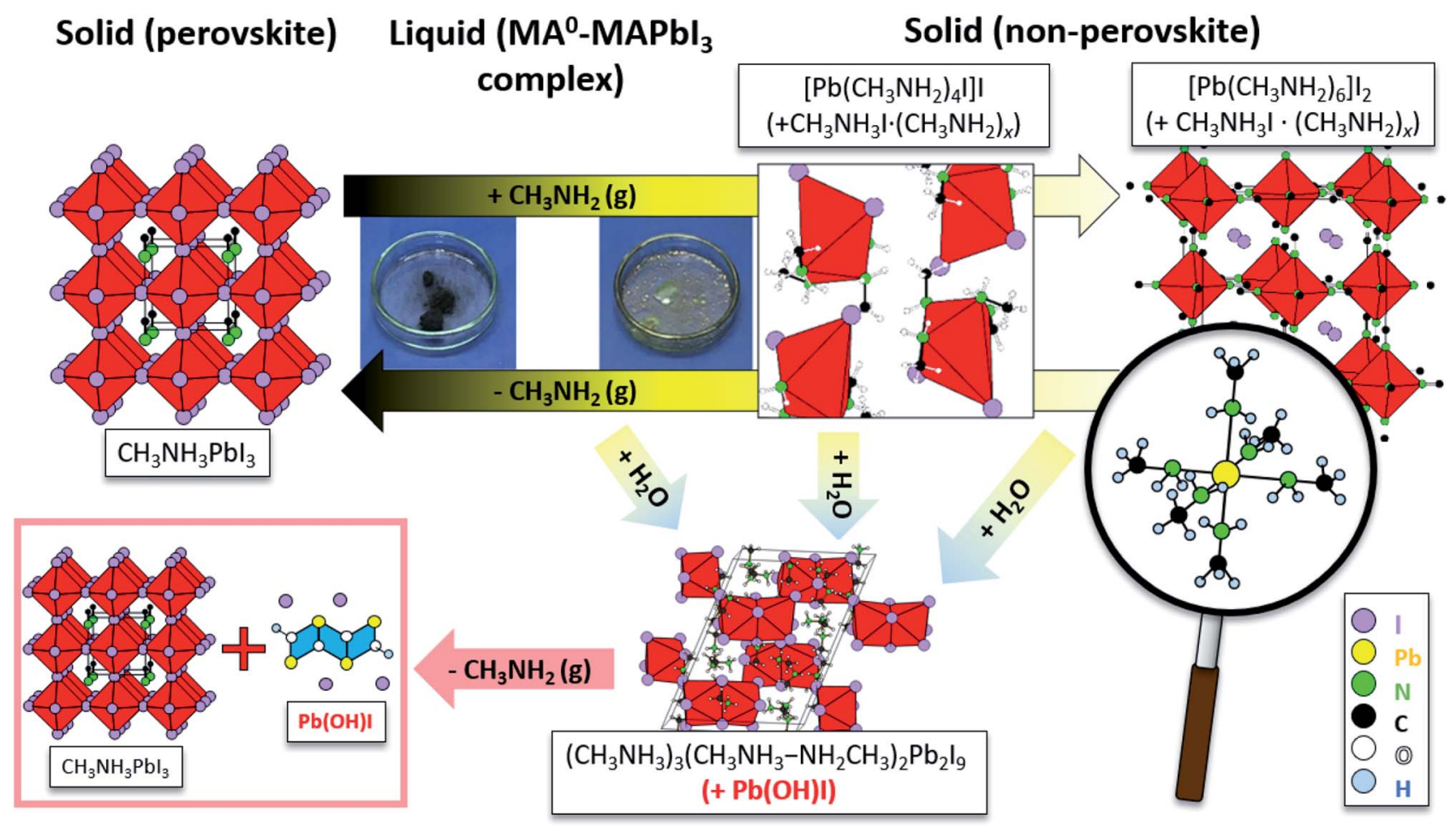

Fig. 3 Structural changes during the liquefaction of $\left.M A P b\right|_{3}$ upon the introduction of $M A^{0}$ and formation of the neutral complex [PbMA $\left.{ }_{4}^{0}\right]$ $\mathrm{I}\left(+\mathrm{MAl} \cdot \mathrm{MA}_{x}^{0}\right)$ in which $\mathrm{Pb}^{2+}$ is coordinated by $\mathrm{MA}^{0}$ molecules. The $\mathrm{MA}^{0}$ amount increase into the complex leads to the increase of coordinated $M A^{0}$ and to the formation of crystalline $\mathrm{PbMA}_{6}^{0} \mathrm{I}_{2}\left(+\mathrm{MAl} \cdot \mathrm{MA} \mathrm{A}_{x}^{0}\right)$. Note that in the presence of humidity a $\mathrm{Crystalline}\left(\mathrm{CH}_{3} \mathrm{NH}_{3}\right)_{3}\left(\mathrm{CH}_{3} \mathrm{NH}_{3}-\mathrm{NH}_{2}-\right.$ $\left.\mathrm{CH}_{3}\right)_{2} \mathrm{~Pb}_{2} \mathrm{l}_{9}$ and $\mathrm{Pb}(\mathrm{OH}) \mathrm{I}$ are produced. Upon further degassing $\mathrm{Pb}(\mathrm{OH}) \mathrm{I}$ stays as an unwanted by-product. These measurements are derived from detailed XRD pattern analysis and visualized via embedded software. 


\section{Real-time crystallization dynamics observed by photoluminescence}

We investigated the crystallization dynamics using real-time photoluminescence microscopy. Such characterization tool allows us to link the emission of photons from radiative recombination with the surface chemistry of the crystallizing layer to understand the behavior of nucleation and absorber layer formation inside the mesoporous scaffold. ${ }^{33}$ A layer of graphite $(12 \mu \mathrm{m})$ on top of thick $\mathrm{ZrO}_{2}$ layer $(2 \mu \mathrm{m})$ on a glass substrate was filled with perovskite solution (MPC with ACN) and subsequently annealed at $70{ }^{\circ} \mathrm{C}$ to crystallize the perovskite. Then, the substrate was placed in a transparent gas chamber (as depicted in Fig. $\mathrm{S} 4 \dagger$ ), to which $\mathrm{MA}^{0}$ gas is later supplied, inducing the perovskite liquefaction. After reaching the liquefied state, a small outlet was opened in the box allowing $\mathrm{MA}^{0}$ gas to leave and upon rise in temperature induced by a transparent hotplate, the methylamine molecules start to evaporate even more rapidly inducing a crystallization within the mesoporous layers. A more detailed description of the setup and the procedure is shown in Fig. S4 and S5. $\dagger$ We ascribe several processes to the different stages observed during the liquid-solid conversion of the perovskite crystals. The real-time PL measurement starts with solid perovskite without $\mathrm{MA}^{0}$ (denoted as stage (i) in Fig. 4). Upon introduction of $\mathrm{MA}^{0}$ to the system, in a first instance the PL sharply rises, reaching a PL intensity 4 times higher than initially and subsequently drops to PL counts close to zero (stage (ii)) since the perovskite now is in a liquified form (stage (iii)). When the $\mathrm{MA}^{0}$ is removed again, the nucleation takes place, and a rise in the PL signal (stage (iv)) is observed,

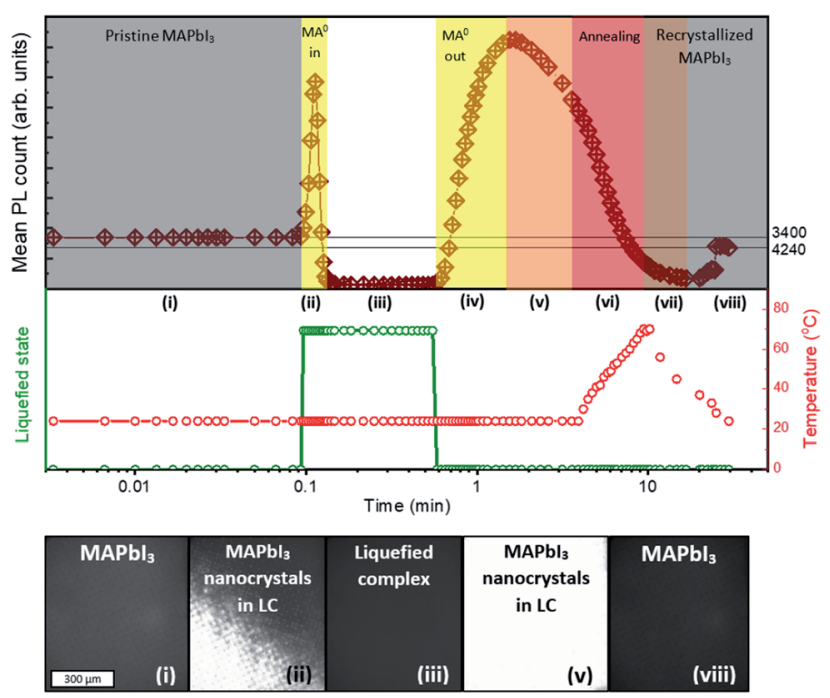

Fig. 4 Investigation of liquid-solid evolution of MPC in mesoporous layers. The photoluminescence is monitored in real-time on the glass/ $\mathrm{ZrO}_{2}$ /graphite device. When the $\mathrm{MA}^{0}$ is supplied through an inlet, the layer turns pale-yellow, causing a drop in the PL signal due to the collapse of the $A B X_{3}$ structure. Once, the inlet is opened, the $M A^{0}$ leaves the MPC, reforming perovskite and causing a rise in $\mathrm{PL}$. When the sample is heated up to $\sim 70^{\circ} \mathrm{C}$, it induces a more rapid leave of $M A^{0}$ and the subsequent crystallization. The full PL microscopy measurement can be found in Video S1 in ESI. $\dagger$ followed by a slow decay (stage (v)) during which the annealing takes place (stage (vi)). After that in the final stages ((vii) and (viii)) the PL signal slightly rises and stabilizes at a value close to the initial one. The real-time PL microscopy measurement is provided in detail in Video $\mathrm{S} 1$ in ESI. $\dagger$

We manifest that the $\mathrm{MA}^{0}$ gas forms the MPC with $\mathrm{MAPbI}_{3}$ via chemisorption of gas molecules to the perovskite crystal lattice by replacing $\mathrm{I}^{-}$atoms, thus coordinating $\mathrm{Pb}^{2+}$ as well as $\mathrm{MA}^{+}$. Therefore, when $\mathrm{MA}^{0}$ is introduced to a perovskite bulk, it diffuses through the grain boundaries and is adsorbed by the crystal surface resulting in the formation of separated nanocrystals. This phenomenon is accompanied by the sharp rise in PL (as seen in stage (ii) Fig. 4), which arises from the reduced number of available bulk recombination centers per perovskite crystal. In literature, high PL in nano-sized perovskite crystals and quantum dots has been observed too. ${ }^{34-36}$ Then the PL signal drops to nearly zero and the absorber layer color becomes transparent-yellow, highlighting that the $\mathrm{ABX}_{3}$ crystal structure is collapsed leading to the inability of the perovskite to have a periodic wave function. Upon the removal of $\mathrm{MA}^{0}$ from the MPC during the crystallization process, the $\left(\mathrm{PbI}_{x} \mathrm{MA}_{6-x}^{0}\right)^{2-x}$ octahedra first start to form into clusters, as the number of free $\mathrm{MA}^{+}$ decreases (seen from the decrease of Raman shift band at $290 \mathrm{~cm}^{-1}$ ), and the number of $\mathrm{MA}^{+}$embedded into the $\mathrm{ABX}_{3}$ structure increases (seen from the increase of band at $120 \mathrm{~cm}^{-1}$ ). We note that $\left(\mathrm{PbI}_{x} \mathrm{MA}_{6-x}^{0}\right)^{2-x}$ are charged species where the total charge of a cluster is determined by the number of residing $\mathrm{I}^{-}$ atoms. These clusters act then as nuclei in the beginning of the crystallization process. The supposed process is sketched in Fig. 5.

Revealingly, the adsorption and desorption of $\mathrm{MA}^{0}$ both tend to increase the PL signal, since the non-radiative recombination mechanisms in bulk are suppressed. Between stages (iv) and (v), when the PL signal reaches its maximum ( $t=1.55 \mathrm{~min})$ the bulk recombination starts to dominate because of crystal growth whereas surface passivation by $\mathrm{MA}^{0}$ starts to fade away, decreasing the overall PL. During the recrystallization for

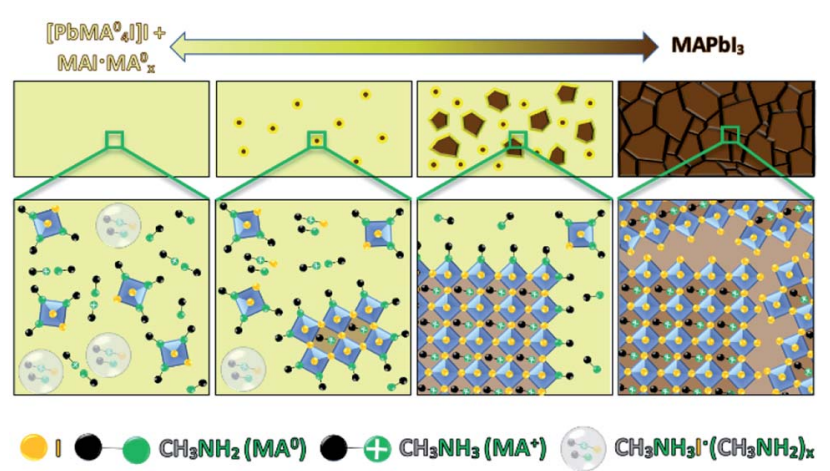

Fig. 5 Schematic illustration of $\mathrm{MAPbl}_{3}$ perovskite recrystallization during desorption of $M A^{0}$ from the methylamine-perovskite complex or crystalline $\left[\mathrm{PbMA}_{4}^{0}\right] \mathrm{I}+\mathrm{MAI} \cdot \mathrm{MA}_{x}^{0}$. The double-sided arrow highlights that the reaction and mechanisms are reversible. The upper row depicts the crystal morphology change, while the bottom row illustrates the interaction of $\mathrm{Pbl}_{6}$ octahedra with $\mathrm{MA}^{0}$ and the by-products in the solution such as MAI-MA $A_{x}^{0}$ and $M A^{+} \cdot M A^{0}$. 
$\sim 20 \mathrm{~min}$, stabilization is reached as is indicated by constant slightly higher PL. During the stabilization, improvement of perovskite quality through the change of grain structure and removal of residual $\mathrm{MA}^{0}$ caused by annealing, has been reported before. ${ }^{14}$ A similar overall trend, where the PL starts to rise, then drops and rises slightly again during annealing until stabilization has been observed also before for the 2-step solution processing, where $\mathrm{PbI}_{2}$ instead of $\mathrm{MA}^{0}$ passivates the grain boundaries ${ }^{\mathbf{1 4 , 3 7}}$ until its complete conversion to the $\mathrm{CH}_{3} \mathrm{NH}_{3}$ $\mathrm{PbI}_{3}$, after which the PL decreases. ${ }^{33,38}$

\section{Influence of $\mathrm{MA}^{0}$ concentration in the MPC solution on the fully-crystallized photoabsorbers}

Accurate estimation of the reaction products during liquefaction is challenging, therefore we quantitatively compare the effect of various given amounts of $\mathrm{MA}^{0}$ in the solution by reacting it with the known quantity of $\mathrm{CH}_{3} \mathrm{NH}_{3} \mathrm{PbI}_{3}$.

We prepared three different solutions using $x$ (ratio of moles of $\mathrm{MA}^{0}$ per moles of perovskite) of 19.2, 14.4 and 11.5. The estimation of $x$ is shown in the ESI. $\uparrow$ The lowest value $(x=11.5)$ already allows the complete melting of the perovskite, whilst $x>$ 20 lead to formation of white precipitates in the solution.

Perovskite films were deposited on glass substrates by spincoating the MPC (diluted with ACN) of different ratios $x$ of $\mathrm{MA}^{0}$ in it. The obtained XRD patterns of each sample are shown in Fig. 6d, where the (110) and (220) diffraction peaks increase with higher concentration of $\mathrm{MA}^{0}$ in the complex, while most of other reflections decrease. Such trend highlights how the concentration of methylamine can directly affect the preferential orientation of the crystal lattice. Looking at the most pronounced diffraction signal of (110) plane, an increase in full-width at half maximum (FWHM) from $0.095^{\circ}$ over $0.119^{\circ}$ to $0.165^{\circ}$ can be observed as the amount of $\mathrm{MA}^{0}$ in the MPC rises. The change in FWHM indicates that by varying the $\mathrm{MA}^{0}$ ratio in the MPC, the
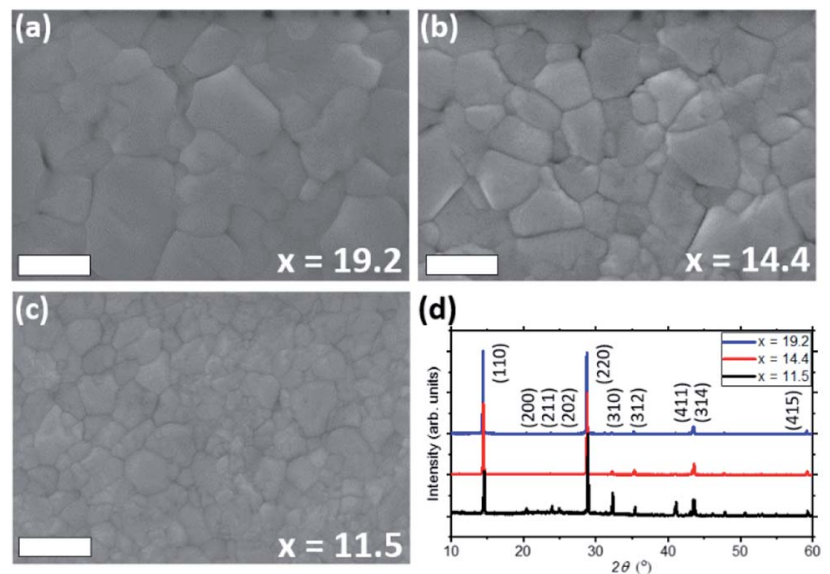

Fig. $6 \mathrm{SEM}$ images of $\mathrm{MAPbl}_{3}$ crystallized from various amounts of $M A^{0}$ in the liquefied $x M A^{0} \cdot M A P b l_{3}$ complex $(a-c)$, where the crystal size increases with higher $M A^{0}$ concentration, which can also be seen from an decrease in FWHM of (110) and (220) diffraction peaks at highly concentrated (with $M A^{0}$ ) samples. The presented XRD patterns of three samples show how strongly $M A^{0}$ coordinates the recrystallization of MAPbl 3 along (110) and (220) planes (d). Scale bar - $300 \mathrm{~nm}$. perovskite grain size can be tuned (i.e. large grain sizes are grown using high amounts of $\mathrm{MA}^{0}$ ), which can also clearly be seen in SEM top-view images in Fig. 6a-c and crystal area distributions (Fig. S7†), obtained by analysing these images via ImageJ.

It has been numerously reported that the change of stoichiometry in the precursor perovskite solution leads to different crystallization dynamics, which can lead to variation in such fundamental material properties as crystal size, charge carrier transport and contact at the interface between perovskite and charge extracting layer. ${ }^{39-42}$ A similar dependency on the solution composition is seen in the MPC, where, as a result of the $\mathrm{MA}^{0} /$ perovskite ratio, crystals with different domain size have been grown which coincides with the observations by Chen et $a l .^{3}$ The differences in FWHM in the XRD measurements correlate with the observations by SEM. We attribute such behavior to a stronger chemical coordination of $\mathrm{Pb}^{2+}$ and $\mathrm{MA}^{+}$ with the higher $\mathrm{MA}^{0}$ concentration, which causes a more preferential orientation of the crystal lattice along $\langle h k 0\rangle$ planes such as (110) and (220), ${ }^{\mathbf{8} 43}$ resulting in the growth of larger crystals. It is worth mentioning that the commonly observed peak at $2 \theta=$ $12.7^{\circ}$ which is usually observed when $\mathrm{PbI}_{2}$ is formed ${ }^{28,37,44,45}$ was absent in all the samples. However, this residual $\mathrm{PbI}_{2}$ could be screened by the formation $\mathrm{PbI}_{2}$-alkylamide impurities, resulting in the reduced carrier lifetime of the crystallized absorber. The peaks at $2 \theta=9.84,^{\circ} 19.74^{\circ}$ and $29.79^{\circ}$ which are attributed to MAI reflections ${ }^{\mathbf{2 8 , 4 6}}$ are also not present, concluding that upon crystallization the MPC forms a pure, stoichiometric $\mathrm{MAPbI}_{3}$ photoabsorber from an additive-free "perovskite melt".

The finding that the morphology of the final crystal layers changes as a function of the $x$ ( $\mathrm{MA}^{0} /$ perovskite) ratio suggests that the crystallization kinetics could also be different within the mesoporous layers of the C-PSCs. While perovskite crystals using MPC can even reach sizes of $>1 \mu \mathrm{m}$ on planar substrate, ${ }^{\mathbf{4 3}}$ the crystal growth inside the porous layers of C-PSCs is clearly different, as the majority of pores have diameters of less than $20 \mathrm{~nm}$. Therefore, crystallization is confined by the pore size, which means that the interface plays a big role in the nucleation process as it provides multiple nucleation sites. ${ }^{47}$ To gain a better understanding of the effect of ratio $x$ in the solution on the crystallized absorber layer in porous isolating $\mathrm{ZrO}_{2}$ scaffold, we use steady-state and timeresolved photoluminescence (TRPL) intensity measurements. A series of perovskite-filled mesoporous layers with different $x$ variations were characterized. As seen from Fig. $S 8, \uparrow$ the steady-state PL intensity image of layers crystallized from a low-concentrated solution show strong PL signal. With higher concentration of $\mathrm{MA}^{0}$ the average number of PL counts decreases, while the overall homogeneity of the PL signal increases as a result of better infiltration in the mesoporous layers. We quantify the homogeneity $(h)$ of the PL image by comparing the histogram of the PL intensity shown in Fig. S9. $\uparrow$ Due to a higher concentration of $\mathrm{MA}^{0}$ in the solution, the liquified complex becomes less viscous enabling an easier infiltration through the pores. Zhou et al. suggested that the excess of $\mathrm{MA}^{0}$ in the MPC "trims" the clusters, leading to a decrease in cluster size and lower viscosity. ${ }^{48}$

A TRPL was employed to derive the carrier lifetime $(\tau)$. Generally, as it has been demonstrated in numerous works, the PL-decay is affiliated with the transient behavior of radiative 
Table 1 The mean PL counts, calculated homogeneity and trapassisted decay lifetime $\tau$ obtained from PL images of absorber layers crystallized from solutions with various $x$ inside mesoporous $\mathrm{ZrO}_{2}$ layers $(a-d)$

\begin{tabular}{lllll}
\hline$x \mathrm{MA}^{0}$ & $x=8.6$ & $x=11.1$ & $x=14.8$ & $x=18.2$ \\
PL (cts) & $6.6 \times 10^{3}$ & $4 \times 10^{3}$ & $3.8 \times 10^{3}$ & $3.8 \times 10^{3}$ \\
Homogeneity & $2.6 \times 10^{-4}$ & $3.3 \times 10^{-4}$ & $7.4 \times 10^{-4}$ & $8 \times 10^{-4}$ \\
$\tau(\mathrm{ns})$ & 273.65 & 140.67 & 20.9 & 22.56
\end{tabular}

and non-radiative recombination of charge carriers in a semi-


the longer the PL-decay, the longer the excited diffusing carriers are present in the perovskite, and therefore the longer carrier lifetime and diffusion length, both of which are vital characteristics of any PV device.

We quantify the charge carrier lifetime by fitting the PLdecay to a bi-exponential function, accounting for Schockley-Read-Hall recombination processes at surfaces and in the bulk. The TRPL results in Fig. S10† show that the decay is much slower (longer carrier lifetime) in the photoabsorbers fabricated with MPC using low ratio of $\mathrm{MA}^{0} / \mathrm{MAPbI}_{3}$ in it (273.65 ns and $140.67 \mathrm{~ns}$ for $x=8.6$ and 11.1, respectively). Contrarily, for the higher ratio of $\mathrm{MA}^{0}$ the PL-decay is significantly faster: $20.9 \mathrm{~ns}$ for $x=14.8$ and $22.56 \mathrm{~ns}$ for $x=18.2$. As seen from Table 1 , large amounts of $\mathrm{MA}^{0}(x>12)$ yield an absorber with lower carrier lifetime having lower averaged PL, indicating that despite strong advantages from crystallographic perspective (as seen from XRD patterns) such ratios of $\mathrm{MA}^{0}$ are not desired due to poor opto-electronic properties of the layers. Conings et al. have also found that the recrystallized layer after the $\mathrm{MA}^{0}$ treatment helps the infiltration through the pores, but, on the other side, leading to an inferior electronic quality. ${ }^{10}$ Since no quenching layers are involved, the observed reduction in carrier lifetime is likely related to a more efficient bulk/surface non-radiative recombination processes. This means that there are either more of faster recombination channels, most likely in the form of trapassisted recombination. Since only the stoichiometry of the MPC changes without introduction of any other additive, the trap capture cross-section (i.e. quenching efficiency of each trap) should remain unchained. We therefore suggest that at high $x$, high number of trap energy states inside the bandgap outweigh the advantages of smoother film and better infiltration and start to play major role in defining the electronic properties of the absorber. Such a dependency of $\tau$ on $x$ emphasizes the importance of a careful control of $x \mathrm{MA}^{0}$ (in reaction (1)) which should be within a certain processing window when producing solutions for perovskite PV devices.

\section{Conclusions}

In this work, the nature of methylamine- $\mathrm{MAPbI}_{3}$ complex formation and its re-crystallization during the degassing in perovskite solar cells is presented. We show through XRD single crystal measurements, that $\mathrm{MA}^{0}$ simultaneously forms neutral complexes with both $\mathrm{Pb}^{2+}$ and MAI leading to the collapse of the perovskite crystal structure. In the excess ( $>1 \mathrm{~atm})$ of $\mathrm{MA}^{0}$ this reaction induces the formation and precipitation of nonperovskite solid crystals of $\left[\mathrm{Pb}\left(\mathrm{CH}_{3} \mathrm{NH}_{2}\right)_{4} \mathrm{I}\right] \mathrm{I}$ and $\left[\mathrm{Pb}\left(\mathrm{CH}_{3}-\right.\right.$ $\left.\left.\mathrm{NH}_{2}\right)_{6}\right] \mathrm{I}_{2}$. We highlight that the presence of $\mathrm{H}_{2} \mathrm{O}$ leads to the irreversible formation of $\mathrm{Pb}(\mathrm{OH}) \mathrm{I}$, which act as impurities in the photoabsorbing layer. Therefore, the formation of pure methylamine-perovskite complex needs to be carried out under normal atmospheric pressure of the $\mathrm{MA}^{0}$, and in the absence of water.

During the degassing of $\mathrm{MA}^{0}$ from the complex, the iodide bonds with $\mathrm{Pb}^{2+}$, forming $\mathrm{PbI}_{6}$ octahedra, while $\mathrm{MA}^{+}$cations get embedded in the A-site of the original pseudo-cubic $\mathrm{ABX}_{3}$ structure. Real-time photoluminescence (PL) microscopy as a measure of the crystal quality visualizes the interaction of $\mathrm{MA}^{0}$ gas with perovskite crystals. We postulate that the liquefaction starts from diffusion of $\mathrm{MA}^{0}$ gas molecules through grain boundaries, leading to a break-up of bulk crystals and therefore reducing bulk recombination. This process is then followed by a complete collapse of the perovskite structure, as the PL signal approaches zero. When the $\mathrm{MA}^{0}$ gas is desorbed afterwards in inert atmosphere, in accordance with the PL recovery a reversible process takes place, where the isolated non-bulk crystals of $\mathrm{MAPbI}_{3}$ start to re-emerge from a liquefied state till the crystal coalescence is complete.

Furthermore, we find that the amount of $\mathrm{MA}^{0}$ in the complex plays a vital role in the control of crystal size and trap-assisted charge carrier lifetime. In planar films with high $\mathrm{MA}^{0}$ concentration, the $\mathrm{MA}^{0}-\mathrm{MAPbI}_{3}$ complex leads to growth of larger crystals, while the low concentration leads to smaller crystals. In perovskite-filled mesoporous layers time-resolved PL decay shows that high amount of $\mathrm{MA}^{0}$ in the complex causes an increase in trap-assisted monomolecular charge carrier recombination suggesting the formation of numerous trap energy states.

With this work we show that the understanding of liquefaction processes and crystallization kinetics is paramount for the further development of perovskite photovoltaics.

\section{Conflicts of interest}

There are no conflicts to declare.

\section{Acknowledgements}

This work has been partially funded within the projects APOLO (Grant Agreement No. 763989) as a part of European Union's HORIZON 2020 Research and Innovation Program, PROPER financed from the German Ministry of Education and Research under funding number 01DR19007 and UNIQUE supported under umbrella of SOLAR-ERA.NET_cofund by ANR, PtJ, MIUR, MINECO-AEI and SWEA, within the EU's HORIZON 2020 Research and Innovation Program (cofund ERA-NET Action No. 691664). D. B. and L. W. acknowledge the scholarship support of the German Federal Environmental Foundation (DBU). The authors thank Jutta Zielonka for conducting the SEM measurements. 


\section{Notes and references}

1 NREL, Best Research-Cell Efficiency Chart, 2019.

2 Z. Zhou, Z. Wang, Y. Zhou, S. Pang, D. Wang, H. Xu, Z. Liu, N. P. Padture and G. Cui, Angew. Chem., Int. Ed., 2015, 54, 9705-9709.

3 Y. Jiang, L. Tu, H. Li, S. Li, S.-E. Yang and Y. Chen, Crystals, 2018, 8(1), 44, DOI: 10.3390/cryst8010044.

4 T. Zhao, S. T. Williams, C.-C. Chueh, D. W. deQuilettes, P.-W. Liang, D. S. Ginger and A. K.-Y. Jen, RSC Adv., 2016, 6, 27475-27484.

5 L. Hong, Y. Hu, A. Mei, Y. Sheng, P. Jiang, C. Tian, Y. Rong and H. Han, Adv. Funct. Mater., 2017, 27, 1703060.

6 Y. Jiang, E. J. Juarez-Perez, Q. Ge, S. Wang, M. R. Leyden, L. K. Ono, S. R. Raga, J. Hu and Y. Qi, Mater. Horiz., 2016, 3, 548-555.

7 C. Li, S. Pang, H. Xu and G. Cui, Sol. RRL, 2017, 1, 1700076. 8 M. Long, T. Zhang, H. Zhu, G. Li, F. Wang, W. Guo, Y. Chai, W. Chen, Q. Li, K. S. Wong, et al., Nano Energy, 2017, 33, 485496.

9 A. J. Ramadan, N. K. Noel, S. Fearn, N. Young, M. Walker, L. A. Rochford and H. Snaith, Chem. Mater., 2018, 30, 7737-7743.

10 B. Conings, S. A. Bretschneider, A. Babayigit, N. Gauquelin, I. Cardinaletti, J. Manca, J. Verbeeck, H. J. Snaith and H.-G. Boyen, ACS Appl. Mater. Interfaces, 2017, 9, 8092-8099.

11 J.-a. Yang, T. Qin, L. Xie, K. Liao, T. Li and F. Hao, J. Mater. Chem. C, 2019, 7, 10724-10742.

12 Y. Zhang, Z. Zhou, F. Ji, Z. Li, G. Cui, P. Gao, E. Oveisi, M. K. Nazeeruddin and S. Pang, Adv. Mater., 2018, 30, e1707143.

13 Y. Zhang, G. Grancini, Z. Fei, E. Shirzadi, X. Liu, E. Oveisi, F. F. Tirani, R. Scopelliti, Y. Feng, M. K. Nazeeruddin, et al., Nano Energy, 2019, 58, 105-111.

14 N. K. Noel, S. N. Habisreutinger, B. Wenger, M. T. Klug, M. T. Hörantner, M. B. Johnston, R. J. Nicholas, D. T. Moore and H. J. Snaith, Energy Environ. Sci., 2017, 10, 145-152.

15 L. Wagner, S. Chacko, G. Mathiazhagan, S. Mastroianni and A. Hinsch, ACS Energy Lett., 2018, 3, 1122-1127.

16 M. Wong-Stringer, T. J. Routledge, T. McArdle, C. J. Wood, O. S. Game, J. A. Smith, J. E. Bishop, N. Vaenas, D. M. Coles, A. R. Buckley, et al., Energy Environ. Sci., 2019, 12, 1928-1937.

17 Q. Liu, Y. Zhao, Y. Ma, X. Sun, W. Ge, Z. Fang, H. Bai, Q. Tian, B. Fan and T. Zhang, J. Mater. Chem. A, 2019, 7, 18275-18284.

18 D. Burkitt, R. Swartwout, J. McGettrick, P. Greenwood, D. Beynon, R. Brenes, V. Bulović and T. Watson, RSC Adv., 2019, 9, 37415-37423.

19 R. F. Warren and W. Y. Liang, J. Phys.: Condens. Matter, 1993, 5, 6407-6418.

20 R. A. Kerner, T. H. Schloemer, P. Schulz, J. J. Berry, J. Schwartz, A. Sellinger and B. P. Rand, J. Mater. Chem. C, 2019, 7, 5251-5259.

21 H. Chen, F. Ye, W. Tang, J. He, M. Yin, Y. Wang, F. Xie, E. Bi, X. Yang, M. Grätzel, et al., Nature, 2017, 550, 92-95.
22 C. Wu, H. Li, Y. Yan, B. Chi, J. Pu, J. Li, M. Sanghadasa and S. Priya, Nano Energy, 2017, 36, 295-302.

23 S. R. Raga, Y. Jiang, L. K. Ono and Y. Qi, Energy Technol., 2017, 5, 1750-1761.

24 R. Essmann, G. Kreiner, A. Niemann, D. Rechenbach, A. Schmieding, T. Sichla, U. Zachwieja and H. Z. Jacobs, Z. Anorg. Allg. Chem., 1996, 622, 1161-1166.

25 R. Nasanen, SUOMEN KEMISTILEHTI, 1966, 39(4), 105.

26 O. I. Siidra, D. Y. Zenko, A. N. Suknotova and S. V. Krivovichev, Mineral. Mag., 2013, 77, 3239-3248.

27 X. Huang, R. Chen, G. Deng, F. Han, P. Ruan, F. Cheng, J. Yin, B. Wu and N. Zheng, J. Am. Chem. Soc., 2020, 142, 6149-6157.

28 S. M. Jain, B. Philippe, E. M. J. Johansson, B.-w. Park, H. Rensmo, T. Edvinsson and G. Boschloo, J. Mater. Chem. A, 2016, 4, 2630-2642.

29 C. Quarti, G. Grancini, E. Mosconi, P. Bruno, J. M. Ball, M. M. Lee, H. J. Snaith, A. Petrozza and F. D. Angelis, J. Phys. Chem. Lett., 2014, 5, 279-284.

30 D.-N. Jeong, D.-K. Lee, S. Seo, S. Y. Lim, Y. Zhang, H. Shin, H. Cheong and N.-G. Park, ACS Energy Lett., 2019, 4, 1189-1195. 31 M. Park, N. Kornienko, S. E. Reyes-Lillo, M. Lai, J. B. Neaton, P. Yang and R. A. Mathies, Nano Lett., 2017, 17, 4151-4157. 32 T. Glaser, C. Müller, M. Sendner, C. Krekeler, O. E. Semonin, T. D. Hull, O. Yaffe, J. S. Owen, W. Kowalsky, A. Pucci, et al., J. Phys. Chem. Lett., 2015, 6, 2913-2918.

33 L. Wagner, L. E. Mundt, G. Mathiazhagan, M. Mundus, M. C. Schubert, S. Mastroianni, U. Würfel, A. Hinsch and S. W. Glunz, Sci. Rep., 2017, 7, 14899.

34 S. Bonabi Naghadeh, B. Luo, G. Abdelmageed, Y.-C. Pu, C. Zhang and J. Z. Zhang, J. Phys. Chem. C, 2018, 122, 15799-15818.

35 Y.-F. Li, J. Feng and H.-B. Sun, Nanoscale, 2019, 11, 1911919139.

36 X. Li, Y. Wu, S. Zhang, B. Cai, Y. Gu, J. Song and H. Zeng, $\mathrm{CsPbX}_{3}$, Adv. Funct. Mater., 2016, 26, 2435-2445.

37 L. Wang, C. McCleese, A. Kovalsky, Y. Zhao and C. Burda, J. Am. Chem. Soc., 2014, 136, 12205-12208.

38 M. Anaya, J. F. Galisteo-López, M. E. Calvo, C. López and H. Míguez, J. Phys. Chem. C, 2016, 120, 3071-3076.

39 V. D'Innocenzo, A. R. Srimath Kandada, M. d. Bastiani, M. Gandini and A. Petrozza, J. Am. Chem. Soc., 2014, 136, 17730-17733.

40 S. I. Seok, M. Grätzel and N.-G. Park, Small, 2018, 14, e1704177.

41 J.-H. Im, I.-H. Jang, N. Pellet, M. Grätzel and N.-G. Park, Nat. Nanotechnol., 2014, 9, 927-932.

42 S. Mastroianni, F. D. Heinz, J.-H. Im, W. Veurman, M. Padilla, M. C. Schubert, U. Würfel, M. Grätzel, N.-G. Park and A. Hinsch, Nanoscale, 2015, 7, 19653-19662.

43 D. L. Jacobs and L. Zang, Chem. Commun., 2016, 52, 1074310746.

44 A. Ummadisingu and M. Grätzel, Sci. Adv., 2018, 4(2), e1701402.

45 J. Burschka, N. Pellet, S.-J. Moon, R. Humphry-Baker, P. Gao, M. K. Nazeeruddin and M. Grätzel, Nature, 2013, 499, 316319. 
46 Z. Song, S. C. Watthage, A. B. Phillips, B. L. Tompkins, R. J. Ellingson and M. Heben, Chem. Mater., 2015, 27, 4612-4619.

47 A. Dunlap-Shohl and Y. Zhou, Chem. Rev., 2019, 119(5), 3193-3295.

48 Z. Liu, J. Hu, H. Jiao, L. Li, G. Zheng, Y. Chen, Y. Huang, Q. Zhang, C. Shen, Q. Chen and H. Zhou, Adv. Mater., 2017, 29, 1606774.
49 S. D. Stranks, G. E. Eperon, G. Grancini, C. Menelaou, M. J. P. Alcocer, T. Leijtens, L. M. Herz, A. Petrozza and H. Snaith, J. Sci., 2013, 342, 341-344.

50 A. D. Wright, R. L. Milot, G. E. Eperon, H. J. Snaith, M. B. Johnston and L. M. Herz, Adv. Funct. Mater., 2017, 27, 1700860.

51 Y. Yamada, T. Nakamura, M. Endo, A. Wakamiya and Y. Kanemitsu, J. Am. Chem. Soc., 2014, 136, 11610-11613. 